\title{
Correction to: Aortic dilatation in children with mild to moderate chronic kidney disease
}

\author{
Peace C. Madueme ${ }^{1}$ - Derek K. $\mathrm{Ng}^{2} \cdot$ Luke Guju $^{3} \cdot$ Lauren Longshore $^{3} \cdot$ Vicky Moore $^{3} \cdot$ Lynn Jefferies $^{4}$. \\ Bradley A. Warady ${ }^{5}$. Susan Furth ${ }^{6}$. Mark Mitsnefes ${ }^{3}$
}

Published online: 8 July 2020

(C) IPNA 2020

\section{Correction to: Pediatr Nephrol (2020) 35:1023-1031 https://doi.org/10.1007/s00467-019-04469-3}

The original version of this article unfortunately contained a mistake. The data presented in Table 5 contained duplicated rows. The corrected version of Table 5 is presented below.

Table 5 Univariate and multivariate results from repeated measures logistic regression to estimate associations of biomarkers with the presence of aortic dilatation

\begin{tabular}{lcc}
\hline & Univariate OR (95\%CI) & Multivariate ${ }^{\mathrm{a}} \mathrm{OR}(95 \% \mathrm{CI})$ \\
\hline Per 1 SD increase in systolic blood pressure (z-score) & $1.16(0.85,1.57)$ & $1.08(0.79,1.46)$ \\
Per 1 SD increase in diastolic blood pressure (z-score) & $2.08(1.39,3.10)$ & $1.98(1.34,2.92)$ \\
Per 1 SD decrease in weight (z-score) & $1.51(1.21,1.87)$ & $1.48(1.21,1.82)$ \\
Per 1 SD decrease in height (z-score) & $1.28(0.95,1.72)$ & $1.24(0.91,1.69)$ \\
Per 1 SD decrease in body mass index (z-score) & $1.65(1.30,2.09)$ & $1.69(1.31,2.17)$ \\
Per 1 SD decrease in estimated glomerular filtration rate (log scale) & $1.35(1.003,1.83)$ & $1.31(0.93,1.86)$ \\
Low hemoglobin vs. normal hemoglobin & $1.74(0.92,3.29)$ & $1.77(0.90,3.45)$ \\
$\geq 2$ positive counts of standard PEW ${ }^{\mathrm{b}}$ vs. $<2$ positive counts of standard PEW & $1.99(0.80,4.96)$ & $1.88(0.77,4.56)$ \\
$\geq 3$ positive counts of modified PEW ${ }^{\mathrm{c}}$ vs. <3 positive counts of modified PEW & $2.57(1.29,5.11)$ & $2.41(1.23,4.70)$ \\
\hline
\end{tabular}

$S D$, standard deviation; $P E W$, protein energy wasting

${ }^{a}$ Adjusting for age, years with CKD, antihypertensive therapy, growth hormone therapy, and low hemoglobin

${ }^{\mathrm{b}}$ Standard PEW definition based on four domains: abnormal biochemistry, reduced body mass, reduced muscle mass, and decreased appetite

${ }^{c}$ Modified PEW definition based on five domains: abnormal biochemistry, reduced body mass, reduced muscle mass, decreased appetite, and poor growth Entries in italics indicate a statistically significant association with increased odds of aortic dilatation

Publisher's note Springer Nature remains neutral with regard to jurisdictional claims in published maps and institutional affiliations.

The online version of the original article can be found at https://doi.org/10. 1007/s00467-019-04469-3

Peace C. Madueme

Peace.madueme@nemours.org

1 The Cardiac Center, Nemours Children's Hospital, 13535 Nemours, Parkway, Orlando, FL 32827, USA

2 Johns Hopkins Bloomberg School of Public Health, Baltimore, MD, USA
Cincinnati Children's Hospital Medical Center, Cincinnati, OH, USA

4 Methodist University of Tennessee Cardiovascular Institute, Memphis, TN, USA

5 Children's Mercy Hospital, Kansas City, MO, USA

6 Children's Hospital of Philadelphia, Philadelphia, PA, USA 